"Justice for Native People, Justice for Native Me": Using Digital Storytelling Methodologies to Change the Master Narrative of Native American Peoples

$\begin{array}{cc}\begin{array}{c}\text { Jillian Fish, PhD } \\ \text { fishx174@umn.edu }\end{array} & \text { Payton K. Counts, BA } \\ \text { Department of Psychology } & \underline{\text { count068@umn.edu }} \\ \text { University of Minnesota, Twin Cities } & \text { Indigenous Peoples Task Force } \\ \text { Minneapolis, MN } & \text { Minneapolis, MN }\end{array}$

Version: 08/10/2020

Author note.

Jillian Fish is now a postdoctoral fellow at the Center for Care Delivery and Outcomes Research at the Minneapolis VA Health Care System and the University of Minnesota's Medical School. We extend our sincerest gratitude to Kate McLean, Moin Syed, Richard Lee, Joseph Gone, and Geoffrey Maruyama for comments on an earlier version of the manuscript. To appear in: K. C. McLean (Ed.), Cultural methodologies in psychology: Describing and transforming cultures. New York: Oxford University Press. 


\begin{abstract}
Native American and Indigenous peoples are the original inhabitants of the U.S., including hundreds of tribes with distinct cultures and histories that inform their epistemological (i.e., ways of knowing) and ontological (i.e., ways of being) worldviews. Despite this, Western peoples continue to story the experiences of Native peoples for them, creating master narratives in which Native peoples are relics of the past, and impoverished, uneducated, drunkards in the present (Duran, 2019). Indeed, this is a longstanding effect of the colonial project that continues to erase the authentic, lived experiences of Native peoples, thus, limiting their self-understanding and future possibilities. To counter these enduring colonial narratives, it is critical Native peoples have access to both Native-centered and community-based spaces in which the complexities of Native identities and experiences can be voiced and storied. OrigiNatives sought to provide urban Native peoples in Minnesota a space that privileged their ways of knowing and being through digital storytelling workshops, in which Native peoples $(n=75)$ from 34 different tribal communities created original and authentic stories of their cultures, histories, and lives using digital media technologies. We review the process of creating and implementing OrigiNatives through partnerships with Native-serving organizations in Minnesota, highlighting implications digital storytelling methodologies have for challenging and resisting coloniality by empowering Native peoples to tell our stories, our way.
\end{abstract}

Keywords: Digital storytelling, master narratives, social justice, Native Americans, identity. 


\section{“Justice for Native People, Justice for Native Me": Using Digital Storytelling Methodologies to Change the Master Narrative of Native American Peoples}

"Justice for Native People, Justice for Native Me

How to write the Great American Indian novel.

All of the Indians must have tragic features: tragic noses, eyes, and arms.

Their hands and fingers must be tragic when they reach for tragic food.

The hero must be a half-breed, half White and half Indian, preferably

from a horse culture. He should often weep alone. ${ }^{1}$

I am as Native as my father. Old-school Native: My father, his mother, and grandmother were not traditionals. They were puritanical, boarding school Christians, and in their legacy, still are. We are not stereotypes or filled with a woodland wisdom. We are jaded and cautious and hardworking, and when we weep, we weep alone.

I am as White as my mother. Staying White through the admission of guilt and the acknowledgement of a depraved indifference. Happily egocentric, immersed in the national fiction. 'I know they suffered tragedy trauma and extreme malfeasance, but they're uneducated and ill-mannered and irresponsible.' Integration, also known as submission, is offered as a compassionate option.

Naive is what I am not. I have not grown in a Native community and have only come in later life to know some Native people and to develop some connection to local Native culture. I don't speak English like a Native or understand local Native cultural norms.

Native is what I am. Brown and black haired, hawk-nose, cheek-boned enough that I am at least a White man's Indian. They know me from my multiple film cameos where I am often drunk, confused, simple minded, and kind. They know me from the historical fiction of their youth where I portray a barbaric loser. I am Native or some type of bipedal forest creature; I am Native because Native is what they are not.

I am for justice for Native people, or at least justice for Native me. Justice for Native me might be not claiming to be Native if you're not. Who do you spend your time with? And what are your physical circumstances in a racist society? Do you have to tell people that you are Native? And does it seem that your doing so gives other White people license to argue that their $1 / 32$ Native blood makes them Native too? Do you suffer as Native or do you gain as Native? Do you fall short as Native or does it lift you up? Does it keep you from having a job or does it get you a job? Is Native a thoughtful choice or a depressing reality?

Justice for Native me is the death of flute music and the discontinuation of the generic image of Sitting Bull. Not equating Native with poverty and ignorance. If I know five words in my traditional language, I am not an Indian. To be Native is not to know a lot about the woods. To

\footnotetext{
${ }^{1}$ Sherman Alexie, "How to Write the Great American Indian Novel” from The Summer of Black Widows.
} 
be Native is not to be part of a fictional hemisphere-wide culture. To be Native is not a casual exploration of my heritage. Justice for Native me is rigorous honesty.

Now I sit with people who are simultaneously Native and not Native and discuss identity decisions based in the tolerable degree of honesty, fearfully designing a comfortable reality. Real but not too real. Comfortably Native, possibly not White, defined by societies that are not our own.

In the Great American Indian novel, when it is finally written, all of the White people will be Indians and all of the Indians will be ghosts.",

- Blair, Oneida Nation of Wisconsin

Blair wrote this narrative for the digital story he created as a part of our digital storytelling (DST) project, OrigiNatives. OrigiNatives provides Native American, Alaska Native, and First Nations people with the opportunity to create original and authentic stories of our cultures, histories, and lives with digital tools and technologies through DST workshops. In an OrigiNatives' workshop, Blair wrote his narrative, recorded an audio voiceover of it, and integrated it with text and background effects to create a short digital story. While OrigiNatives is a social justice, emancipatory project that places the power to shape what it means to be Native in the hands of Native peoples through digital media and storytelling, it is also a research project that enables psychologists to gain a more nuanced understanding of Native peoples' identities and the master and alternative narratives we contend with throughout identity development. Indeed, Blair's narrative depicts a clear tension between Western society's conception of what it means to be Native and alternative notions of Nativeness, which Blair refers to when articulating what being Native means to him. Similar to other digital stories created in OrigiNatives, Blair describes a constellation of master and alternative narratives that inform his personal narrative. Through DST, Blair provides the audience with powerful insight into how we configure our identities through negotiating with the stories that are told about us and the stories that are told by us. 
Accordingly, the goal of this chapter is to discuss the emancipatory power of DST methodologies in changing the master narrative of Native peoples, specifically in the context of OrigiNatives. Towards this end, we provide an overview of longstanding narratives of Native peoples in the U.S. within the master narrative framework (McLean \& Syed, 2015), highlighting implications master narratives have on Native peoples' identities, which serves as the impetus for OrigiNatives. Following this, we discuss the development and implementation of OrigiNatives, detailing how our use of DST methodologies gives voice, freedom, and opportunities to Native peoples to shape narratives about their communities in psychological research and the broader public. Throughout the chapter, we include ourselves as active agents in the research process, who occupy both the roles of researchers and community members. While it is common for psychology researchers to situate themselves as separate from the communities that they conduct research with, we intentionally situate ourselves with Native peoples, as we are, in fact, Native researchers. This is critical to our anticolonial approach to changing the master narratives of Native peoples, in which we challenge narratives that Native peoples are not successful in education or other domains of functioning through our actual research, but also through our own positionality. We outline the procedures we used for facilitating OrigiNatives as a communitybased project with Native peoples and refer to our experiences during the project to demonstrate the various ways community members engaged with DST as a tool to counter and resist Western concepts of Native identities.

For readers conducting research with Native American and Indigenous communities, we envision this as a guide towards psychological research and dissemination that is both for and by Native peoples. Thus, we refer to companion materials throughout the chapter that are available for readers to access and use on the Open Science Framework (OSF) page for OrigiNatives (see 
https://osf.io/4zsh6/). Readers can also access a limited digital archive that includes digital stories from eight of the community members who participated in OrigiNatives (see https://umnlatis.github.io/digital-stories/), including digital stories from Blair, Erin, Kirby, Marcie, Mo, Rory, Serena, and Travis. Though we reference excerpts or content from their digital stories throughout the chapter, we invite you to view each of their digital stories in their entirety to experience the full transformative potential of digital tools and story-based data gathering strategies for Native peoples and their communities, as we describe below.

\section{Stories and the Self}

The stories we are told about us are a tool for understanding ourselves as cultural and historical entities. Stories are transmitted within and between cultures, and across generations, from one historical cohort and context to the next. Stories that accomplish this cultural and historical transmission of ways of knowing (i.e., epistemologies) and being (i.e., ontologies; Wilson, 2001) serve as the foundation of individuals' identities (Chandler \& Lalonde, 1998; Fish \& Syed, 2018; Hilton \& Liu, 2017; see also Manago, Santer, Barsigian, \& Walsh, this volume; Rogers, Moffitt, \& Jones, this volume; Weststrate, this volume). Thus, stories can be thought of as a cultural and historical repository individuals engage with throughout identity development. Narratives tell individuals from a given community or cultural background where their culture has been (past), where it is now (present), and where it could go (future; Chandler \& Lalonde, 1998; Chandler et al., 2003; Fish, 2018) - allowing individuals to transcend time, space, and place to achieve a richer self-understanding in a larger cultural and historical context (Syed \& Mitchell, 2015).

An example of temporal transcendence is reflected in Blair's narrative (Story 1), as he extends backwards in time, several generations in fact, to understand who he is as a Native 
person in the present and the potential for justice in the future (Chandler \& Lalonde, 2008;

McAdams \& McLean, 2013; Singer, 2004). In addition to transcending time, Blair's narrative allows him to transcend space, to the places (i.e., boarding school) that shaped his forebeaerers, and therefore, him. The remaining narratives from the digital stories included in Figure 1 describe similar temporal and spatial transcendental qualities. For Erin (Story 2), hearing stories from elders in Diné (i.e., her tribal language) transports her to a spiritual plane, where she comes to the realization that her Diné culture as an inextricable part of her. Whereas for Kirby (Story 3), traditional knowledge (e.g., the Seven Grandmother and Grandfather Teachings) actually comes forward in time through his own grandamother and shows him how to live. For Marcie (Story 4), she travels to the past to access spirits, ancestors, and elders' songs for guidance for fostering the resilience of future generations who have yet to be born. In Mo's narrative (Story 5), they make sense of their lifetime trauma perpetuated by extended family members through a collective past of historical and intergenerational trauma. Similarly, Rory (Story 6) visits and connects past his(stories) of genocide to present day relations between the U.S. government, corporations, and Indigenous peoples. In Serena's narrative (Story 7), stories are like a DeLorean - a fictional timetravel vehicle from the Back to the Future movie franchise - that brings her back in time to see and feel her father's experience being beaten in boarding school for speaking the Ojibwe language, shedding light on the significance of her pursuing language studies in the present. Much like Travis outlines in his narrative (Story 8), stories allow authors to traverse time and effectively establish elements of their present selves as legacies of past experiences. While these are just a few examples from the digital stories that are a part of OrigiNatives, we can begin to see how historically- and culturally-salient stories can empower and liberate Native peoples to live more self-determined futures, and full and authentic lives. 
While all stories are capable of shaping our ways of knowing and being, some stories exert a stronger influence than others, such as master narratives (McLean \& Syed, 2015). Master narratives are "culturally shared stories that tell us about a given culture, and provide guidance for how to be a "good" member of a culture" (McLean \& Syed, 2015, p. 320). Master narratives are defined through five interrelated principles. First, master narratives have utility because they illustrate how to be part of society. Second, master narratives are known for their ubiquity, as they are common stories among a cultural group. Third, master narratives are often invisible; difficult to see and unconsciously internalized, which is a paradox, as master narratives are often everywhere. Fourth, master narratives are compulsory in nature, as they are value-laden and represent how to exist in a "good" way. Fifth, master narratives are rigid. Though culture is constantly evolving, master narratives evolve less. Consequently, master narratives can be thought of as a cultural and historical blueprint for members from particular communities to fit into a broader societal structure. They are often practical for those living lives that complement this societal structure, and are more problematic for those whose lives do not, such as Native peoples. In these instances, assuming an alternative narrative might be necessary, which occur in constrast to master narratives and differ from them in varying degrees (McLean \& Syed, 2015).

According to the master narrative model, personal narratives can be understood by the extent to which individuals position themselves in relation to master and alternative narratives (McLean \& Syed, 2015). Personal narratives hinge on two psychological processes - 1) negotiating the self as connected to and distinct from a community, and 2) internalizing master narratives, consciously or unconsciously. We see the former through Blair's connections to and distinctions from Native culture, as evidenced through the language he uses to associate and contrast with notions of Nativeness (e.g., "Native is what I am" and "Native is what I am not", 
respectively). The latter process, internalization, taps into the limitations that master narratives impose on agency. For instance, Blair's personal narrative is inundated with references to Western concepts of what it means to be Native American, suggesting these concepts have been internalized to an extent. An example of which can be seen when he notes that Native peoples are "defined by societies that are not our own." While Blair is explicit about his awareness of how society defines what it means to be Native for Native peoples and the limitations it imposes on a given individual, this can also be more subtle. Next, we continue elucidating these processes through illustrations of well-known master narratives of Native peoples, demonstrating the power that stories about us have in shaping our self-understanding.

\section{Stories About Us: Master Narratives of Native Americans}

As Native peoples, we are often expected to fulfill antiquated historical roles (Fryberg et al., 2008), live in impoverished conditions on reservations with financial support from the government or casinos (Houska, 2017), and as drunks (Duran, 2019; Fish et al., 2017b). Blair negotiates with master narratives like these throughout his narrative, noting "We are not stereotypes or filled with a woodland wisdom", as Native peoples are often seen as having extraordinary spiritual characteristics and connections to nature (Duran, 2019). Additionally, Blair suggests that others know him through master narratives; because he is "brown [...], blackhaired, hawk-nose, cheek-boned enough" to be a "White man's Indian", people assume him to be "drunk, confused, simple-minded, and kind" and a "barbaric loser." Indeed, psychological research has demonstrated representations of Native peoples are often rooted in negative stereotypes (Fryberg et al., 2008). Though not the same as master narratives per se, dominant representations provide shared ideas about the "good" or "right" way to be a person (Fryberg \& Townsend, 2008), and communicate master narratives of Native peoples. As Blair references, 
master narratives of Native peoples occur in film ("They know me from my multiple film cameos where I am often drunk, confused, simple minded, and kind"), literature ("They know me from the historical fiction of their youth where I portray a barbaric loser", the Sherman Alexie excerpt), and music and imagery ("Justice for Native me is the death of flute music and the discontinuation of the generic image of Sitting Bull"). Sources of representations are often "societies that are not our own" and can be found throughout Western cultures.

These sentiments are best articulated by Dr. Joseph Gone, who states, "Indians are simultaneously everywhere and nowhere. There are sports mascots on TV, and the streets and states are named after Indians. But if you survey most Americans, they don't know any Indian people and can only come up with a historical figure like 'Crazy Horse' or 'Sitting Bull' or 'Chief Joseph"” (Dhar \& Gone, 2019, no pagination). Blair echoes this when he describes Sitting Bull as a "generic image" and its "death" as justice for Native peoples. For Blair, it seems that master narratives erase Native peoples by imposing stories about us over stories that are by us. Thus, when you hear stories by us that are not consistent with master narratives, then we cannot possibly be "real" Native peoples, and voila, we are erased. While this is problematic for several reasons, a major reason is that master narratives of Native peoples are anachronistic, which is a non-coincidental legacy of colonialism (Fish et al., 2017a). Since the beginning of colonization, Native peoples have been told that to be "good" is to be nonexistent (e.g., "The only good Indian, is a dead Indian"; Mieder, 1993). While literal (i.e., genocide of Native American and Indigenous peoples in the Americas), it is also a metaphor for the broader colonial project and efforts to eliminate Native peoples through means such as assimilation. Efforts to assimilate - or civilize and Christianize - Native peoples were often carried out through boarding schools, which as Carlisle Indian School founder, Captain Richard H. Pratt notes, were intended to "Kill the 
Indian, save the man" (Churchill, 2004; Fish \& Syed, 2018; Glenn, 2015). Blair alludes to this process when describing himself in terms of the legacy of generations of his family - including his father, grandmother, and great-grandmother - whom he refers to as "puritannical, boarding school Christians."

Most, if not all, of the master narratives we have described are rooted in a long, enduring history of colonialism, which continues to be perpetrated and upheld in the present by people in powerful positions, who benefit from their endurance (e.g., the majority owner of the NFL's Washington team, Daniel Snyder, receives financial compensation for the erasure and oppression of Native peoples through the team's name and mascot; the U.S. government continues to appropriate land and resources of Native peoples through the Dakota Access Pipeline in Standing Rock and Enbridge Line 3 in the Ojibwe communities in Minnesota). Master narratives of Native peoples, such as these, are influential determinants of what it means to be Native, erasing and homogenizing the hundreds of tribes in the U.S. (Fryberg \& Townsend, 2008), their rights, and sovereignty. Much like Wolfe (2006) states of settler colonialism, master narratives "destroy to replace" (p. 388). Consequently, Native peoples from diverse tribal communities - like both of the authors who are from different tribes with different cultures and histories - are left to negotiate their identities with monolithic and outdated master narratives. As a result, master narratives constrain self-understanding and possibilities for the future within the context of contemporary life (Leavitt et al., 2015), limit Native people's academic and professional identities (Covarrubias \& Fryberg, 2015), and lead to Native peoples imagining futures characterized by failure and impoverishment (Fryberg \& Markus, 2003). Despite their enduring nature, it is possible to change master narratives, which as we discuss next, we set out to accomplish through our DST project, OrigiNatives. 


\section{Stories By Us: Digital Storytelling in Native America}

While the stories that are told about us have great potential to shape our personal narratives, so do the stories that are told by us. Psychological research has demonstrated selfrelevant representations and alternative narratives that underscore the complexities of Native identities (cf., local, national, and global configurations of Native identities; Markstrom, 2011) can counteract the effects of master narratives (Covarrubias \& Fryberg, 2015). The literature also suggests Native peoples are best positioned to explore what it means to be Native through spaces and places that privilege Native ways of knowing and being (Fish \& Syed, 2018), such as within Native communities (Lysne \& Levy, 1997). Thus, we aimed to provide Native peoples with a Native-centered space through OrigiNatives workshops, where we used DST methodologies to give voice to stories that have been long oppressed in and by Western societies.

DST has been used to conduct research with Indigenous peoples including the Māori (Beltrán \& Begun, 2014), Inuit (Cunslo Willox et al., 2013) and Alaska Natives (Cueva et al., 2015; Cueva et al., 2016), Metis and First Nations (Iseke, 2011), and Native peoples from both urban areas and reservations (Blue Bird Jernigan et al., 2012; Manuelito, 2015) to do just that; to give us the power to shape our own narratives. The tribal communities DST has been used with include Cherokee (Powell et al., 2007), Paiute (Corwin, 2016), Kiowa (Palmer, 2016), and Ojibwe (Manuelito, 2015), and the various tribal communities represented in OrigiNatives (see Table 1). Some DST projects, like $n$ DigiDreams, have worked with over 80 tribes in producing more than 1,200 digital stories (Manuelito, 2015), whereas Project Life has helped over 500 Alaska Native students create digital stories (Wexler et al., 2013).

DST methodologies are used to address various research questions related to Native identity and self-understanding. For instance, DST research projects have queried cultural 
strengths (rather than deficits; Beltrán \& Begun, 2014; see also Hamby, this volume; Katsiaficas, this volume), explored domains of Native identity, such as what it means to be a treaty person (Couros et al., 2013), and has been used as a tool that enhances Native identities (Gray et al., 2010). Other examples include using DST to capture stories of resilience in the context of historical trauma (Beltrán \& Begun, 2014), of wellbeing in communities with high rates of cancer (Cueva et al., 2016), and of fortitude and strength in the face of suicide (Wexler et al., 2013). Digital stories such as these invite alternative notions of Nativeness into identity development, shedding light on the successes, resilience, and strength of Native peoples, rather than deficits alone (Fish \& Syed, 2018). As Blair suggests with the Sherman Alexie excerpt, master narratives of Native peoples are often deficit focused, highlighting tragedy or trauma (Benish-Weisman, 2009), which grounds stories in the tragic flaws of Native peoples, or characterizes them as victims who are helpless and hopeless.

DST is ideal for shifting master narratives because it recognizes the will and determination of Native peoples as active co-constructors of their lived experiences. Not only does DST effectively center storytelling practices and traditions seen in various tribal communities (Cunsolo Willox et al., 2012), but it does so towards the end of emancipating Native peoples from colonial power dynamics in research, placing the power in the hands of community members to author their own narratives on topics that are often authored for them (Palacios, 2012). Indeed, DST gives community members a sense of agency (Blue Bird Jernigan et al., 2012), providing them a space to use their voices to advocate for themselves and their communities (Burgess, 2006; see also Delker, this volume for a similar discussion regarding survivors of trauma), which for Blair, is justice for Native peoples. Simultaneously, DST acts as an intervention that promotes individual and community change. As best described by Palacios 
and colleagues (2015), DST transmits notions of culture and identity across generations, while also educating, empowering, and motivating people to make positive and adaptive changes.

Despite its widespread use with Native peoples in the humanities and social sciences, DST is seldom used with Native peoples in psychology, with the exception of Moorehead (2014) who facilitated a DST project with urban Native peoples from the San Francisco Bay Area. This may be due to the ambiguities and lack of specificity associated with DST methodologies (Fish \& Syed, under review). While this arguably provides researchers with a degree of flexibility in initiating DST projects in terms of how to best address research questions and the needs of the local community, it can also be daunting for psychologists operating within framworks (e.g., positivistic, postpositivistic, and constructivist) that grant more methodological specificity (Fish \& Syed, under review). Whereas DST occurs within a critical paradigm, which tends to be less empirical and more consistent with humanistic scholarship, emphasizing inequities wrought from societal structures and the power within them (Ponterotto, 2005). More specifically, DST is considered a participatory research method within the critical paradigm, a set of methods that focuses on diverse lived experiences, ways of knowing, disrupting power dynamics, relationship building, and contextual information (Baum et al., 2006; Cornwall \& Jewkes, 1995; Hacker, 2013; see also Katsiaficas, this volume). Thus, individuals are not simply participants, but community members with insight and knowledge about addressing social issues in their communities, who researchers partner with to elevate their voices in creating solutions for change (Freire, 1996; Smithies \& Webster, 1998; Worthen et al., 2019).

Participatory approaches like DST can be particularly powerful for understanding identity formation among Native peoples, which has been described as a complex process that requires Native and non-Native psychologists to go beyond measuring traditional markers of identity 
(e.g., ethnic identity, bi-cultural identity; Markstrom, 2011). While these are tried-and-true facets of identity that are measured in psychology, understanding the nuances and complexities of Native identities necessitates measuring other features of Native peoples' identities, including their connectiosn to their tribe, clan, spirituality, cultures, histories, land, kinship bonds, and ancestors (Gone, 2006; Gone et al., 1999; Markstrom, 2011). With DST methodologies, psychologists can effectively empower Native peoples with opportunities to nurture these facets of the self with their own words and lived experiences, and invite them to be a part of the research process. In turn, psychologists are then provided with culturally rich and nuanced firstperson narrated accounts of Native peoples' lives (Cunsulo Willox et al., 2012). Now, we continue to unpack the DST methods we used in OrigiNatives as a legitimate approach to conducting psychological research with Native peoples that has the potential to change the narrative of Native peoples in the U.S. That is, what stories are told about us and by whom.

\section{OrigiNatives: Our Stories, Our Way}

Formerly known as the Native American Digital Storytelling Project, OrigiNatives was first established in 2018. OrigiNatives is a mobile, DST project that travels to different places to empower Native peoples to tell our stories, our way. We renamed the project OrigiNatives as a play on the word originative, defined as "having the ability to originate: creative" (MerriamWebster, 2020). Thus, the name OrigiNatives is intended to reflect our mission, which is to provide a Native-centered digital space that gives voice to original and authentic digital stories from the original peoples of the U.S. (Duran, 2019). In turn, we intended to use the digital stories created as a part of OrigiNatives to answer the following research questions: 1) What cultural representations are present in narratives from urban Native peoples? 2) How do urban Native peoples internalize and resist cultural representations through digital storytelling? While the 
former sought to pinpoint representations of Native peoples' cultures that are salient to them, the latter question was intended to tease apart the narrative processes individuals use to engage with such representations when developing a sense of self. As a participatory project, community members had full creative discretion over their digital stories, which we anticipated would provide more than sufficient data for answering our research questions. Part of our anticipation was rooted in the potential that DST have to afford psychologists with culturally-rich, firstperson narratives, while the other was rooted in our first-hand experience with another digital storytelling project, Immigrant Stories.

OrigiNatives was modeled off of Immigrant Stories (https://immigrantstories.umn.edu/). First launched in 2013, by the University of Minnesota's Immigration History Research Center (IHRC), Immigrant Stories captures digital stories of modern day migration. Additionally, it aims to build a digital archive of and increase accessibility to historic materials on migration to preserve for future generations. Through Immigrant Stories, individuals learn how to create a digital story about a migration experience by writing an original narrative, recording an audio voiceover of it, and selecting images, videos, and music to create a 3-5 minute digital story. The Immigrant Stories' website includes workshop guides for creating digital stories, as well as curriculum and lesson plans for teaching about the digital stories from the project. To date, the digital archive includes more than 300 digital stories from over 50 international communities, which are from individuals who chose to donate their digital stories to IHRC. As mentioned earlier, we have a limited digital archive that includes eight digital stories that were donated to OrigiNatives. Indeed, we hold Immigrant Stories in high regard, as it serves as the framework for our approach to the DST methodologies we used in OrigiNatives. The first author was initially 
exposed to Immigrant Stories as a research assistant; knowledge and experience from which we used to create and implement OrigiNatives, as we describe below.

\section{Community Members and Partnerships}

From June 2018 through March 2019, OrigiNatives facilitated 22 workshops in partnership with 11 Native-serving organizations in Minneapolis, Saint Paul, and Duluth, MN. Seven were non-profit organizations and three were public schools, colleges, or universities. Additionally, eight of these organizations were located in Minneapolis, two were located in Saint Paul, and one was located in Duluth. While we had an ongoing partnership with one of the Minneapolis organizations that served as the main host site for OrigiNatives workshops, we fostered additional partnerships throughout the project to host other workshops in conjunction with (see Allen, Rivkin, \& Trimble, this volume; Hamby, this volume; and Katsiaficas, this volume for discussions of fostering relationships with community partners). Community members who were 18-years of age or older were recruited to participate in OrigiNatives workshops through several mechanisms, including our community partners, recruitment flyers and emails, in person, and word-of-mouth.

There was a total of 77 community members who participated in OrigiNatives, 75 of which completed their digital stories in the workshop, which was our final sample. Though optional, 68 community members granted us permission to reproduce, distribute, and publicly exhibit their digital stories. Our sample represents 34 different tribal communities and affiliations (see Table 1), which was determined based on responses to an open-ended question ("What is your tribal affiliation?"). To avoid colonial power dynamics that exclude Native peoples based on blood quantum or tribal enrollment, community members could participate based on selfidentification. Moreover, we chose not to exclude two community members who did not disclose 
their tribal affiliations. One participant did not feel comfortable disclosing her tribal affiliation due to the degree of erasure she had experienced, whereas the other denied knowing her tribe, citing erasure. Indeed, excluding community members from participating in OrigiNatives due to erasure - an effect of historical trauma (Brave Heart et al., 2011) - would be antithetical to our mission and an extension of the colonial project.

In addition to tribal diversity, OrigiNatives served community members across the lifespan, with community members ranging in age from 19 to 80 . While the majority of community members were between 30 - and 39 -years old, there was, at a minimum, $10 \%$ of community members participating from each age bracket. Thus, it seems that OrigiNatives appealed to adults of all ages. Though we required community members to be 18 -years old to participate for research purposes, some community members brought their underage children to create a digital story with them, which we permitted as a Native-centered space to promote intergenerational sharing and healing among family members. Indeed, it was quite common for community members to sign up for OrigiNatives workshops with family members or friends, including parent-children dyads and extended family. Our sample was mostly female (71\%) with an associate's degree, bachelor's degree, or its equivalent (53\%), and employed full-time (52\%; see Table 2 for all demographic information and descriptive statistics).

\section{Creating a (Digital) Space for Native Stories}

Much like the power Immigrant Stories has to capture rich and nuanced stories of migration, we wanted OrigiNatives to provide a similar opportunity for Native peoples to story, share, and preserve aspects of their lives - including their cultures and histories. Towards these ends, we completed a thorough and critical examination of Immigrant Stories in order to adapt it to meet this vision. Though we describe this process here, there is a more thorough description of 
our adaptation on the OSF page, including our original workshop guide and step-by-step research protocol.

\section{Workshop Structure}

As described in the materials on the OSF page, we ultimately adapted OrigiNatives into a one-day workshop after receiving feedback from our community partners. While two- to threeday workshops are ideal for creating digital stories, we needed to balance this with the needs of the community, as longer workshops could be a barrier to attendance for community members who have familial or work responsibilities. Additionally, we did not want OrigiNatives to pose a burden to the Native-serving organizations we partnered with, since workshops would take valuable resources, like time and space, from organizations and the Native peoples they serve. During OrigiNatives workshops, community members created a digital story; a short multimedia production that integrates various forms of digital media to tell an original, personal story (Fish $\&$ Syed, under review). The main steps include writing a personal narrative, recording and editing an audio voiceover of the narrative, and combining it with pictures, videos, and music. To reduce barriers to participating and for OrigiNatives to be truly accessible to all Native peoples, we provided all of the necessary equipment to create a digital story, as well as support and guidance throughout the creation process (see DST Concepts, Definitions, and Supplies on the OSF page for a complete list of equipment).

\section{Epistemological and Ontological Adaptation}

While these structural elements were critical to the success of OrigiNatives, what was more important were epistemological and ontological adaptations. To be able to engage in a paradigm-shifting research project, it was necessary that we, too, shift our methodological approach to facilitate this process. Much like Audre Lorde (1979) states that "the master's tools 
will never dismantle the master's house" (p. 110), we believe the colonist's tools will never dismantle colonial systems. Accordingly, integrating Native ways of knowing and being were a necessary component of OrigiNatives (see also Wilson et al., this volume), for the project would be a repackaging of colonial marginalization without them. When adapting the various materials available through the Immigrant Stories website, we did so bearing the needs of Native peoples in mind, at the level of the culture (i.e., Native peoples) and subculture (i.e., Native communities in Minnesota). Accordingly, we were constantly questioning, how could OrigiNatives most effectively empower local Native peoples, with an eye towards the broader Native population? This was a reflexive process that we engaged in throughout the project, in which OrigiNatives was evolving on a regular basis as a result of lessons learned during workshops and insights gleaned from community members.

As Native researchers, it was not uncommon for us to use our own ways of knowing and being as a starting point for adapting Immigrant Stories for OrigiNatives. For example, we were immediately struck by the potential of DST to affirm Native peoples' epistemologies, including the oral tradition and storytelling as methods for learning and knowledge production (Garroutte, 2005; Duran, 2019; Duran \& Firehammer, 2015). For Native American and Indigenous peoples, Maori scholar Linda Tuhiwai Smith (2012) describes the focus of story-based data gathering strategies as being "on dialogue and conversations amongst ourselves as indigenous peoples, to ourself and for ourselves [...] Their themes tell us about our cultures” (p. 145). Take, for instance, when the first author learned of her own tribe's migration story, which was first conveyed to her through an oral story from a tribal member. Oral histories such as this enable Native peoples to learn about themselves in a broader cultural-historical context. 
While the storytelling aspect of DST resonated with us and our community partners, the digital component remained less clear. Was this still the oral tradition if stories are being digitized? Moreover, a community member (who was not a participant) shared that he was taught that storytelling was considered a wintertime activity, whereas our project went year round. This was a teaching we were familiar with given our time in the community and our own teachings. Consequently, we realized it was important for us to distinguish what OrigiNatives was to community members. While it was not traditional in itself, OrigiNatives pulled on storytelling and oral traditions (Duran, 2019). Whereas we considered the digital aspect of storytelling as an opportunity for Native peoples to engage in self-determination by taking control of their images, videos, voices, and music to provide representations that can challenge culturally dominant storylines (Iseke \& Moore, 2011; Moorehead \& LaFromboise, 2014) - something that both of us knew well has been long denied of Native peoples. Thus, OrigiNatives would be an act of resistance and survivance, as the digital stories produced in the workshops would tell stories of Native peoples that often go unheard in the broader society and ultimately, would resist common conceptions of Native America. As one community member told me during the onboarding process, "I want to participate in this workshop because my story matters."

Towards this end, additional adaptations of OrigiNatives centered on creating a Nativecentered space where not only community members' ways of knowing (i.e., storytelling) mattered, but where their ways of being (i.e., cultural practices) did too (Hartmann \& Gone, 2012). Thus, OrigiNatives included the use of traditional medicines (i.e., sage, cedar) to smudge at the beginning of the workshops, which was not a feature of Immigrant Stories. Since workshops involved sharing stories of community members' lives and cultures, one participant recommended smuding as it felt necessary throughout the workshop for purposes of purification. 
Additionally, we opened and closed our workshops with a talking circle, in which we sat in a circle with community members and shared sequentially in a clockwise order. During this time, we often facilitated a locating exercise, in which we described ourselves in relation to our tribal communities, our histories, and our cultures. While these are common pan-Indian practices that we were both familiar with, the locating exercise was a practice the first author learned from her clinical work at the Indian Health Board to facilitate relationships, which as we discuss later, is a central feature of OrigiNatives.

\section{Bringing Power Into Balance}

We were careful to balance our adaptation with the knowledge that we were from tribal communities and geographic areas with different historical and cultural foundations than that of the Native communities OrigiNatives would serve. As a result, it was necessary that we viewed the $5+$ years of experience we acquired working with and serving Native communities in Minnesota through this lens. Accordingly, we often pivoted between who we are as Native researchers, the Native peoples and communities we intended to serve, and the intersection of the two. While psychologists often wonder how we negotiated the line between being researchers and community members ourselves, we take care to remind them that participatory methods seek to take power from researchers and give it to community members (Smithies \& Webster, 1998; see also Katsiaficas, this volume). Thus, pivoting to our role as community members ourselves was often done with intention to replace the assumption of "us as experts" with "community members as experts."

This was a somewhat familiar process. While the context was different, there were past instances in which we have been in community with individuals we also worked with where there were clear power differentials. For instance, the first author (as a community member) 
volunteered at the Boys \& Girls Club for four years while simultaneously completing clinical training at the Indian Health Board in the same neighborhood. Thus, it was not uncommon to do psychotherapy with a child or adolescent who was an active member of the Boys \& Girls Club or who the first author knew. In this instance - and in OrigiNatives - it is imperitive to be clear on dual relationships, differences in roles, and ethical guidelines so that community members can make an informed decision about entering into a relationship with a person who is not simply a psychologist, but also a member of the community (Society of Indian Psychologists \& García, 2014). This sort of dual relationships carries with it a significant degree of power, thus, constant awareness of it and distributing as much of the power as possible into community members hands is vital.

In the case of OrigiNatives, we found that knowing us helped community members feel more at ease when sharing intimate stories of their lives. For community members who did not know us, it sometimes took them longer to attend a workshop because their participation necessitated relationship building (Walters et al., 2020). Two community members come to mind who experienced grave government (e.g., boarding schools, Indian Health Services) betrayals in their lifetimes and who connected with me through email, text messaging, and phone calls for 57 months before attending an OrigiNatives workshop. Another community member with new insight into her experiences with historical trauma met us in person several times while we were at host sites for workshops before participating herself. At their respective workshops, they shared similar feelings of uncertainty regarding their attendence. Were we truly invested in the community? Could we be trusted? For decades, social scientists have visited tribal lands to conduct research to eventually leave and the community itself is left with no direct benefit from the research. Consequently, relationality and accountability was central to OrigiNatives, wherein 
reciprocal relationships between ourselves, the community, and community members was central to our decolonial approach (Duran, 2019; Society of Indian Psychologists \& García, 2014; see also Allen et al., this volume).

Moreso, since psychotherapy similarly involves community members telling stories of their lives - which psychologists are often looked at as the expert in - shifting the psychotherapy power imbalance requires constant reminders that the individual is the author and expert of their own experiences, capable of making changes and decisions that are best for them (Vera \& Spleight, 2003). Similar to the first author's experience with this at the Indian Health Board, we provided community members with constant reminders that their digital story is truly their story. Community members could use a series of open-ended unstructured story prompts we provided or they could write their narrative without them. Similarly, while we recommended stories to be between 300-500 words, this was simply a recommendation and the narratives ranged from 271 to 2,791 words. Needless to say, we did not want to limit community members' digital stories. Community members often wanted us to read their narratives before recording them and tended to ask, "How should I end my story?". After hearing this question for the first time, we quickly learned that despite our efforts to decrease power imbalances, community members still looked to us for guidance. Knowing our responses could influence community members stories, we pointed them to the digital stories that community members gave us permission to share from previous OrigiNatives workshops. We also asked community members, "What do you want others to know about your life?" as this was a common message participants ended their stories with, which proved to be a powerful method for community members pushing back against commmon conceptions of what it means to be Native.

\section{Stories and Relationality}


As we have alluded to throughout, a key component of the OrigiNatives' workshop experience was relationality. OrigiNatives - in and of itself - was an ecosystem; community members interacted with the workshop space and the people within it, and vice versa (Fish \& Syed, 2018). However, community members also engaged with the space, place, characters, and time of their stories, and their stories with them (Fish, 2020). In other words, stories were living and breathing features of OrigiNatives that individuals interacted with and processed, which occurred both intra- and interpersonally. Like an intricate web, community members and their stories reciprocally influenced one another, as well as us. This changed from workshop to workshop, as each workshop involved a different group of community members and research assistants, and was hosted in different spaces and places. Creating digital stories and sharing our lives with one another was one and the same - and often started long before the workshop during the onboarding process, which is where most community members gave insight into the story they wanted to share during OrigiNatives. In the workshop itself, community members listened to one another's stories and at times, helped in the editing process. Community members often read their final narratives out loud before recording them, which was encouraged to for individuals to get a felt sense of telling their story. On several occasions, we have sat with community members while they have cried speaking truth to power in stories that have been pushed to the margins in mainstream society, erased from the pages of history books, and have gone otherwise unspoken.

The pictures and videos that community members brought to OrigiNatives to help tell their stories were just as powerful as the story-sharing itself. While some community members had their media stored online, quite a few individuals brought in photo albums, newspapers, and even objects to take pictures of during workshops. As mentioned earlier, community members 
choosing the photos, videos, and music to include in their digital stories are a form of selfdetermination, in which individuals compile imagery that is an accurate reflection of their lives (Moorehead, 2014; Vivienne, 2011; Vivienne \& Burgess, 2013). While this is quite different than traditional narrative projects, it is necessary for OrigiNatives to reach its full transformative power. The photos, videos, and music used to create a digital story tells their own stories in and of their self, but they also are curated to help tell the story that community members are sharing. Thus, while digital media can be seen as stories within stories, they are selected and arranged in a given digital story to provide a visual aid to the audience (see also Manago et al., this volume). Most importantly, the combination of images, videos, music, and the voiceover recording create a self-relevant representation of community member's lives, that when shared with others, carries the potential to combat the effects of master narratives (Covarrubias \& Fryberg, 2015; Fish, 2020; Moorehead \& LaFromboise, 2014).

Indeed, making real, human connections through stories - whether it was pictures, narratives, sharing, or community members' final digital stories - was the cornerstone of the OrigiNatives' experience. While this permeated each of our workshops, it was most memorable when this connection was deepened through the presence of family and friends in OrigiNatives. An instance of this that was particularly memorable was when we facilitated a workshop in Minneapolis and a community member remarked that her family would love to participate in OrigiNatives. We later received an email from this community member's family, indicating that several of them wanted to attend OrigiNatives when we came to Duluth. Several weeks later in Duluth, we facilitated a workshop with four members of this individual's family, including her two sisters, her mother, and her aunt who was in town from Alaska. The family came in with bags of photos, a bushel of apples to share with us, magazine clippings, a master's thesis on 
Chippewa music, cultural objects, and their stories. This particular family's excitement radiated throughout the workshop as they opened and closed photo albums and shared memories with one another, with pictures sprawled out on the tables. Six months later, the family reported that OrigiNatives helped them open-up about the ways in which historical trauma trickled down to influence their lived experiences, which was not previously discussed prior to the workshop. For workshops in which community members brought family members or friends, we were privileged to bear witness to the strengthening of kinship bonds and intergenerational healing that allows for the forging of new relationships, not only with the family members and friends who were physically in the room, but also spiritually, to ancestors who were on another plane of existence (Walters et al., 2011). Thus, resulting in digital stories that push back against stories of frayed family relationships, and replaces them with narratives of healing.

\section{Challenges to Implementing DST Methodologies}

OrigiNatives garnered interest and support from the Native communities we served (over 150 community members contacted us about the project and community members that participated provided generally positive feedback informally and at a 6-month follow-up). However, it did not come without its challenges. Mirroring the adaptation process, there were structural challenges, as well as process challenges that we encountered during OrigiNatives. For the former, challenges included the space available in the community organizations where we conducted workshops, which we had little control over. Thus, finding a quiet space for recording audio voiceovers could pose a challenge for producing high-quality recordings. Most other structural challenges included issues with technology (i.e., microphones, Internet), and balancing the amount of time we had available in a one-day workshop with community members creating a digital story they were satisfied with. As we mentioned earlier, two community members did not 
finish their digital stories in the workshop due to time limitations and were not able to return to future workshops to complete their stories. Though these issues could pose barriers to creating digital stories, we could often address structural challenges with flexibility and through creative problem-solving (e.g., meeting with community members one on one to finish their digital stories, having them attend a second workshop).

Process challenges that we encountered, however, required a different approach. Similar to our approach to adapting Immigrant Stories into OrigiNatives, we often found ourselves pivoting between our positions as Native researchers, the Native community's position as participants, and the intersection between ourselves and the community as more complex challenges to implementation occurred. For instance, as we mentioned earlier, it was common for us to know our participants from previous interactions in the community, or for participants to know one another. While this may seem odd since traditional methodological approaches confer a degree of "distance" between investigators and participants, we expected this due to our roles in the local communities. For instance, we have been engaged with the Minneapolis, Saint Paul, and Duluth Native communities in various capacities for several years. Accordingly, we negotiated the line between being researchers and community members ourselves with careful consideration of the power of our positions in the context of sharing marginalized stories. As Blair describes towards the end of his narrative, community members are discussing vulnerable topics with one another to the extent that they feel comfortable. Consequently, we sought to create an OrigiNatives culture that honored community, transparency, respect, and trust.

Indeed, OrigiNatives decreased the distance between research, investigators, and participants, literally and figuratively. While this was accompanied with challenges to navigating what is considered an unconventional research environment (i.e., the workshop milieu), 
decreasing the power dynamics in research was necessary to our anticolonial project.

OrigiNatives accomplished this through ongoing efforts to take power away from us, as researchers, and give power to community members, designating them as experts. As Native peoples, we have been systematically dispossessed of our livelihoods (i.e., land, sovereignty, people). There have been countless instances of Western peoples breaking promises to and treaties with Native peoples, as well as occasions in which information taken from Native peoples have been used to harm tribal communities (Simpson, 2014). Thus, we anticipated that OrigiNatives might be met with skepticism, as we are not from the Native communities that the project occurred in, despite our enduring presence in them. It was not uncommon for some community members to be hesitant to participate in OrigiNatives or to have their own challenges creating a digital story. As a result, it was critical for us to keep this cultural and historical context in mind when establishing trust with community members. This was especially important when supporting people who found writing their narrative or using the technology challenging, as these are potentially new experiences for communities who have been deprived of opportunities to use their voice for generations and historically silenced (Dhar \& Gone, 2019).

\section{Lessons Learned and Best Practices}

As mentioned earlier, OrigiNatives was an evolution in multiple senses. It is an outgrowth of Immigrant Stories, maintaining several of its original elements and adding more nuanced features to workshops as OrigiNatives continued to traverse new spaces and places, and historical and cultural contexts. Through this reflexive process, we have learned a great deal about being effective in facilitating OrigiNatives workshops. Broadly speaking, this includes the importance of being familiar with well-established DST projects (i.e, Immigrant Stories) to guide your own, developing the technical skills involved in DST, and adequately preparing community 
members for the workshop experience. However, we have learned much more about working with and in Native communities, centering the needs of our participants, over and above our own as researchers. Accordingly, most - if not all - of the minutiae associated with DST is available on the OSF page (see workshop guide and step-by-step research protocol), as we privilege our critical reflections about OrigiNatives here, such as shifting researcher epistemological and ontological worldviews.

Major elements of OrigiNatives included Native ways of knowing and being, which contrasts with the epistemological and ontological frameworks of mainstream psychological research paradigms - but it does not have to. As Native peoples who have been trained in the latter, we know this all too well. OrigiNatives was a space where this friction was unavoidable, which gave way to opportunities to practice bridging these two metaphorical worlds - the Indigenous and the Western psychological. Indeed, I (J. Fish) vividly remember a community member completing survey measures as a part of OrigiNatives, to which she responded "these are White man questions" about the Historical Loss Scale and the Historical Loss Associated Symptoms Scale (Whitbeck et al., 2004). ${ }^{2}$ This was not new feedback, as other community members had described having emotional reactions to these questions. As Native peoples trained in Western institutions, we are taught that our ways of knowing (i.e., through stories) and being (i.e., the practice of storytelling) are inadequate and undervalued, and must always be legitimized through Western epistemologies (i.e., survey measures) and ontologies (i.e., symptoms), towards the end of pathologizing Native peoples (Duran, 2019; Fish \& Syed, 2018; Trimble, 1987). Thus, this community member's assessment was accurate; we were taking information from her through colonial methods to validate our anticolonial ones.

\footnotetext{
${ }^{2}$ Community members responded to survey measures before attending OrigiNatives' workshops. While the survey measures are not the focus of community members' DST experiences, we did administer common measures used in cultural psychology to explore in the sample.
} 
I (J. Fish) could know from this woman's narrative about intergenerational boarding school attendance and domestic violence that she had experienced historical trauma - and I could know this from her story alone. Her responses to the Historical Loss Scale and the Historical Loss Associated Symptoms Scale could also tell me this, but these measures could not tell me is about her resilience and self-determination - including that she loves the beat of the drum and dancing at powwows, and that she went to law school and became a lawyer to represent her tribe and help her people. Stories are a legitimate form of data that empower community members to tell their stories, their way, without limiting their experiences to the degree of historical trauma that they have experienced. Indeed, Western psychological research creates its own master narrative about Native peoples, which DST can effectively counter, so long as researchers can practice epistemic and ontological humility. For instance, I (J. Fish) told this community member she did not have to complete the survey measures - and she didn't. She created a fantastic digital story instead (see Story \#60), and still remains in contact with me to this day. Other participants similarly did not feel comfortable responding to these measures (and sometimes the other measures, too) before meeting me. Thus, although we asked community members to complete a questionnaire comprised of traditional survey measures before attending the workshop, they did not have to and did not have to respond to the measures at all. To truly center Native ways of knowing and being in research, we must honor them through our actions too.

Other examples of honoring the epistemological and ontological worldviews of participants includes being flexible to orientations to time and learning, which could require you to diverge from Western psychological research protocols that tend to be rigid and constraining for reasons related to methodological rigor. While we understand the need for uniform protocols, such rigidity could further marginalize participants in a space that is intended to do the opposite 
and could be quite damaging. For instance, an elder once wanted to participate in OrigiNatives, but did not have reliable transportation, and wanted to connect with me (J. Fish) before creating her digital story. Thus, I traveled to meet with her three times (twice to connect with one another and once to create her digital story). At our third meeting, we sat on her couch in her apartment, which is where she shared her life, pictures, laughs, and food with me while we created her digital story. Ultimately, she created a digital story (see Story 23) about being a child of rape, her life's work ending violence against Native women, and wanting Native women to know where to find support - in community and through the Women of Nations.

On another occasion, a man named Michael called me about OrigiNatives, stating enthusiastically, “There's a story I've been waiting to tell for years and this seems like the perfect time to do it." We worked together during an OrigiNatives workshop and on two other occasions to create his digital story about his drum, which as he describes it, "is a true testimony to how a drum could make a person feel whole" (see Story 47). Michael immediately shared his story on YouTube (see The Sherman Miracle, https://youtu.be/A6iMkZAx88E) with hopes that other Native peoples would benefit from hearing his story, in which he overcomes a lifetime of tragedy and achieves a sense of wholeness. ${ }^{3}$ While it was not common for participants to create their digital stories one-on-one or over the course of several days, it is important to remember that digital stories are peoples' lives. As Michael states of his own narrative, stories such as the ones created in OrigiNatives are a testament to the determination of Native peoples to negotiate their own futures. When the colonial project has sought to eliminate Native peoples, disenfranchising and silencing our stories for centuries, the stories of community members are

\footnotetext{
${ }^{3}$ Two community members chose to share their digital stories on YouTube immediately after creating them, the second of which includes Story 65 (see This Road Called Life, https://youtu.be/TO77PCtdAx4).
} 
not to be rushed, limited, or abridged in the name of research. This approach to working with and in a community to story their experiences is not only rigorous, it is also justice.

\section{Conclusions: Towards Justice for Native People}

Blair ends his narrative stating that we, Native peoples, are "defined by societies that are not our own," referring to a Sherman Alexie (1996) excerpt that describes the completion of the colonial project as the disappearance of Native peoples. Without question, Western peoples have sought to eliminate Native peoples through various means since the onset of colonialism, sentiments of which are reflected in the stories told about Native peoples in the present day, leading to devastating master narratives of Native Americans. As articulated by Gone, "With historical trauma, it is about entire communities that have been deliberately impoverished and are in need of desperate remedies. This may look less like healing and more like justice" (Dhar \& Gone, 2019, no pagination). As we learned through OrigiNatives, stories are not only a potential remedy for Native peoples, but also a form of justice - one that provides community members with a platform to speak truth to their collective and personal cultures and histories to forge a new future.

Whereas the act of storytelling, in and of itself, demonstrated to be a powerful mechanism for healing, OrigiNatives provided Native peoples with the space and tools to negotiate with Western notions of what it means to be Native - opportunities which community members may not have been afforded in the past. During our second OrigiNatives workshop, an elder came in to create a digital story. He stood in front of me (J. Fish) with his photo albums tucked underneath his arm and said, "You know, I've never talked about much of this before, or even thought about it. I started writing my story, then I stopped and cried a bit, looked through my pictures and cried some more, then I went back to writing my story. It changed how I thought 
about my life" (Story 27). Indeed, OrigiNatives is much more than a research project and is first and foremost a community project, that is for and by the people; simultaneously healing and liberating Native peoples from the legacy of colonialism. Centering culture and community enabled participants to fully engage, reflect on, and question the stories that constituted their sense of selves, empowering them to give voice to experiences often deemed illegitimate or invisible in Western society.

Indeed, OrigiNatives encouraged community members to put into words the ways in which the colonial project has failed, with as Blair describes, "rigorous honesty." This is, in fact, justice for Native peoples as articulated by Native peoples. Diverging from common approaches to research with Native peoples, where information is taken from communities and disseminated in the research literature with little to no direct benefit to Native communities (Duran, 2019), OrigiNatives was truly for Native peoples. Notably absent from this chapter are tradtional research findings resulting from analyses of the digital stories, which is intentional. While we conducted several analyses on the written narratives from the digital stories, including narrative analyses (i.e., content, process, and structure) facilitated via thematic analysis (Braun \& Clarke, 2006), coding for the extent to which community members elaborated on master and alternative narratives in their stories (see McLean et al., 2017), and mixed-methods analyses regarding the the aforementioned qualitative findings and the quantitative findings from the traditional survey measures, the findings are largely a reiteration of what we have articulated here, just perhaps with greater specificity and through the lens of Western psychological knowledge (see Fish, 2020 for in depth findings). ${ }^{4}$ This is not to say that traditional psychological findings are not useful or valuable, however, transforming psychological paradigms - and ultimately, cultures -

\footnotetext{
${ }^{4}$ There are countless possibilities for data analysis for DST projects, which extends beyond the scope of this article. See Fish \& Syed (under review) for more information on different types of analyses.
} 
necessitiates thinking of psychological research differently and truly centering community members as knowledge carriers.

Rather than conduct research and interpret findings with consideration of Native peoples, we invited Native peoples to be a part of the research process to create micro- and macro-level changes in OrigiNatives. It is no longer adequate to write about Native peoples; instead, it is necessary we give opportunities to Native peoples to author their own experiences in efforts to move towards justice and away from colonialism. Justice for Erin (Story 2) is that Native peoples are still here - as is she - despite suffering hardships, which is only one part of the story of what it means to be Native. Kirby's (Story 3) version of justice is truly knowing Native peoples, including acknowledging the original inhabitants of the land, a common oversight in history lessons and textbooks. For Marcie (Story 4), justice is Native peoples being more resilient than our trauma. While it was common for community members to discuss historical trauma in their digital stories, it was equally common for them to talk about resilience, strength, and perseverance, as evidenced through Mo’s (Story 5) and Rory's (Story 6) digital stories, and many others. Through OrigiNatives, community members could leverage their lived experiences as Native peoples to challenge the master narrative that our communities consist solely of tragedy. Justice for Native peoples is much more than community members creating digital stories - it is the potential these stories have to transcend time, reclaiming and restorying Native peoples experiences, including those beyond their lifetime. While stories are a form of medicine to the community members participating in OrigiNatives, stories can also speak into existence histories that have long been oppressed, creating a resilient foundation for future generations. In Serena's (Story 7) digital story, she speaks about her father enduring physical abuse for speaking his language at a boarding school as the cultural and historical context anchoring her own 
commitment to learning the Ojibwe language and teaching it in the future. Similarly, Travis (Story 8) describes how generations of family military service within the cultural and historical context of Native Americans' longstanding involvement in the military impacted his decision to enlist and continues to guide his role in his tribal community. As an avenue for justice to counter the enduring effects wrought by colonialism, digital stories have the potential to be cultural and historical artifacts for those that follow, prompting a shift towards authentic and self-generated narratives of Native peoples.

Conclusively, OrigiNatives is an indicator of the power of storytelling in a digital era, enabling Native peoples to determine their pasts, presents, and futures, defining what it means to be Native on their own terms and in their own ways - and most importantly, in community. We are still in the process of harnessing the full potential of community members' digital stories in transforming institutional and individual knowledge about Native America, which we plan to do by creating a full digital archive of the 68 digital stories community members consented to share. Then eventually, structuring curricula around the content of the stories. We invite and encourage you to watch the available digital stories, as decolonization can only be accomplished when we challenge our epistemological and ontological worldviews and make space for those of others, which OrigiNatives is a first step towards.

\section{Acknowledgements}

We extend our sincerest gratitude to the community members who participated in OrigiNatives. Nyà:wę and miigwech (“Thank You” in Skarú:rę'/Tuscarora and Anishinaabe/Ojibwe, respectively) for sharing your stories and lives with us, and a special thanks to the 68 community members who decided to share their digital stories with the larger community. Additionally, we want to acknowledge our our community partners, who made 
much of this work possible, including the Minneapolis American Indian Center, the American Indian Community Housing Organization, the American Indian Cancer Foundation, Elder's Lodge, Indigenous People's Task Force, the Little Earth Youth Development Center, the Takoda Institute, the Division of Indian Work, the American Indian Family Center, the American Indian Student Cultural Center, and Minneapolis College. We also would like to acknowledge the support we received for OrigiNatives from a Grand Challenges Exploratory Research Grant from the University of Minnesota. In addition, we thank Darien Ruzzicone and Ighedosa Ogbeide for their assistance facilitating workshops. Lastly, we thank Dr. Moin Syed for reading and providing comments on an earlier version of this manuscript. 


\section{References}

Alexie, S. (1996). The summer of black widows. Brooklyn, NY: Hanging Loose Press.

Allen, J., Rivkin, I. D., \& Trimble, J. E. (2020). Relational methodology. In K. McLean (Eds.) Cultural Methodologies in Psychology: Describing and Transforming Cultures. New York: Oxford University Press.

Baum, F., MacDougall, C., \& Smith, D. (2006). Participatory action research. Journal of Epidemiology \& Community Health, 60, 854-857.

Beltrán, R., \& Begun, S. (2014). "It is medicine": Narratives of healing from the Aotearoa Digital Storytelling as Indigenous Media Project (ADSIMP). Psychology \& Developing Societies, 26, 155-179.

Benish-Weisman, M. (2009). Between trauma and redemption: Story form differences in immigrant narratives of successful and nonsuccessful immigration. Journal of Cross-Cultural Psychology, 40, 953-968.

Blue Bird Jernigan, V., Salvatore, A. L., Styne, D. M., \& Winkleby, M. (2012). Addressing food insecurity in a Native American reservation using community-based participatory research. Health Education Research, 27, 645-655.

Brave Heart, M. Y. H., Chase, J., Elkins, J., \& Altschul, D. B. (2011). Historical trauma among indigenous peoples of the Americas: Concepts, research, and clinical considerations. Journal of Psychoactive Drugs, 43, 282-290.

Braun, V., \& Clarke, V. (2006). Using thematic analysis in psychology. Qualitative Research in Psychology, 3, 77-101.

Burgess, J. (2006). Hearing ordinary voices: Cultural studies, vernacular creativity and digital storytelling. Continuum: Journal of Media \& Cultural Studies, 20, 201-214.

Chandler, M. J., \& Lalonde, C. E. (1998). Cultural continuity as a hedge against suicide in 
Canada’s First Nations. Transcultural Psychiatry, 35, 191-219.

Chandler, M. J., \& Lalonde, C. E. (2008). Cultural continuity as a protective factor against suicide in First Nations youth. Horizons, 10, 68-72.

Chandler, M. J., Lalonde, C. E., Sokol, B. W., Hallett, D., \& Marcia, J. E. (2003). Personal persistence, identity development, and suicide: A study of native and non-native North American adolescents. Monographs of the Society for Research in Child Development, 68 (2), Serial No. 273.

Churchill, W. (2004). Kill the Indian, save the man: The genocidal impact of American Indian residential schools. San Francisco, CA: City Lights.

Cornwall, A., \& Jewkes, R. (1995). What is participatory research? Social Science \& Medicine, $41,1667-1676$.

Corwin, J. N. (2016). Indigenous ways of knowing, digital storytelling, and environmental learning - A confluence of tradition and new media technology $(\mathrm{PhD}$ Disseration, Cornell University). Retrieved from https://ecommons.cornell.edu/bitstream/handle/1813/43640/jnc22.pdf?sequence=1

Couros, A., Montgomery, K., Tupper, J., Hildebrandt, K., Naytowhow, J., \& Lewis, P. J. (2013). Storying treaties and the treaty relationship: Enhancing treaty education through digital storytelling. International Review of Qualitative Research, 6, 544-558.

Covarrubias, R., \& Fryberg, S. A. (2015). The impact of self-relevant representations on school belonging for Native American students. Cultural Diversity and Ethnic Minority Psychology, 21, 10-18. 
Cueva, M., Kuhnley, R., Lanier, A., Dignan, M., Revels, L., Schoenberg, N. E., \& Cueva, K. (2016). Promoting culturally respectful cancer education through digital storytelling. International Journal of Indigenous Health, 11, 34-49.

Cueva, M., Kuhnley, R., Revels, L., Schoenberg, N. E., \& Dignan, M. (2015). Digital storytelling: A tool for health promotion and cancer awareness in rural Alaskan communities. International Journal of Circumpolar Health, 74, 1-6.

Cunsolo Willox, A., Harper, S. L., Edge, V. L., 'My Word': Storytelling and Digital Media Lab, \& Rigolet Inuit Community Government. (2012). Storytelling in a digital age: Digital storytelling as an emerging narrative method for preserving and promoting indigenous oral wisdom. Qualitative Research, 13, 127-147.

Delker, B. C. (2020). Interpersonal violence in context: A call to consider cultural stigma in theory and research. In K. McLean (Eds.) Cultural Methodologies in Psychology: Describing and Transforming Cultures. New York: Oxford University Press.

Dhar, A. (Interviewer) and Gone, J. (Interviewee). (2019, October 18). When healing looks like justice: An interview with Harvard psychologist Joseph Gone [Interview transcript]. Retrieved from Mad in America: Science, Psychiatry, and Social Justice website: https://www.madinamerica.com/2019/10/healing-looks-like-justice-interviewharvard-psychologist-joseph-gone/

Duran, E. (2019). Healing the soul wound: Counseling with American Indians and other Native people (2nd ed.). New York, NY: Teachers College Press.

Duran, E., \& Firehammer, J. (2015). Story sciencing and analyzing the silent narrative between words: Counseling research from an indigenous perspective. In Decolonizing “multicultural” counseling through social justice (pp. 85-97). New York, NY: Springer. 
Fish, J. (2020). Systems of cultural representation: An examination of Native American identity and cultural representations through digital stories (unpublished doctoral dissertation). University of Minnesota, Twin Cities.

Fish, J. (2018, August). Honoring indigenous cultures and histories [video file]. Retrieved from https://www.ted.com/talks/jill_fish_honoring_indigenous_cultures_ and_histories?language $=\mathrm{en}$

Fish, J., Livingston, J. A., VanZile-Tamsen, C., \& Wolf, D. A. P. S. (2017a). Victimization and substance use among Native American college students. Journal of College Student Development, 58, 413-431.

Fish, J., Osberg, T. M., \& Syed, M. (2017b). "This is how we were raised": Alcohol beliefs and acculturation in relation to alcohol consumption among Native Americans. Journal of Ethnicity in Substance Abuse, 16, 219-245.

Fish, J., \& Syed, M. (2018). Native Americans in higher education: An ecological systems perspective. Journal of College Student Development, 59, 387-403.

Fish, J., \& Syed, M. (under review). Digital storytelling methodologies: Recommendations for a participatory approach to engaging underrepresented communities in interdisciplinary psychological research. Journal of Counseling Psychology.

Freire, P. (1996). Pedagogy of the oppressed (revised). New York, NY: Continuum.

Fryberg, S. A., \& Markus, H. R. (2003). On being American Indian: Current and possible selves. Self and Identity, 2, 325-344.

Fryberg, S. A., Markus, H. R., Oyserman, D., \& Stone, J. M. (2008). Of warrior chiefs and Indian princesses: The psychological consequences of American Indian mascots. Basic and Applied Social Psychology, 30, 208-218. 
Fryberg, S. A., \& Townsend, S. S. M. (2008). The psychology of invisibility. In G. Adams, M. Biernat, N. R. Branscombe, C. S. Crandall, \& L. S. Wrightsman (Eds.), Decade of Behavior. Commemorating Brown: The social psychology of racism and discrimination (p. 173-193). American Psychological Association. https://doi.org/10.1037/11681-010

Garroutte, E. M. (2005). Defining “radical indigenism” and creating an American Indian scholarship. Culture, Power, and History: Studies in Critical Sociology, 9, 169-198.

Gone, J. P. (2006). Mental health, wellness, and the quest for an authentic American Indian identity. In T. M. Witko (Ed.), Mental health care for urban Indians: Clinical insights from Native practitioners (pp. 55-80). Washington, DC: American Psychological Association. https://doi.org/10.1037/11422-003

Gone, J. P., Miller, P. J., \& Rappaport, J. (1999). Conceptual self as normatively oriented: The suitability of past personal narrative for the study of cultural identity. Culture \& Psychology, 5, 371-398.

Gray, N., Oré de Boehm, C., Farnsworth, A., \& Wolf, D. (2010). Integration of creative expression into community-based participatory research and health promotion with Native Americans. Family \& Community Health, 33, 186-192.

Glenn, E. N. (2015). Settler colonialism as structure: A framework for comparative studies of US race and gender formation. Sociology of Race and Ethnicity, 1, 52-72.

Hacker, K. (2013). Community-Based Participatory Research. Thousand Oaks, CA: SAGE Publications.

Hamby, S. (2020). Strengths-based approaches to conducting research with low income and other marginalized populations. In K. McLean (Eds.) Cultural Methodologies in Psychology: Describing and Transforming Cultures. New York: Oxford University Press. 
Hartmann, W. E., \& Gone, J. P. (2012). Incorporating traditional healing into an urban American Indian health organization: A case study of community member perspectives. Journal of Counseling Psychology, 59, 542.

Hilton, D. J., \& Liu, J. H. (2017). History as the narrative of a people: From function to structure and content. Memory Studies, 10, 297-309.

Houska, T. (2017). The Standing Rock resistance and our fight for Indigenous rights [video file]. Retrieved from https://www.ted.com/talks/tara_houska_the_standing_rock_ resistance_and_our_fight_for_indigenous_rights\#t-53114

Iseke, J. M. (2011). Indigenous Digital storytelling in video: Witnessing with Alma Desjarlais. Equity \& Excellence in Education, 44, 311-329.

Iseke, J., \& Moore, S. (2011). Community-based Indigenous digital storytelling with elders and youth. American Indian Culture and Research Journal, 35, 19-38.

Katsiaficas, D. (2020). Participatory action research with immigrant-origin youth. In K. McLean (Eds.) Cultural Methodologies in Psychology: Describing and Transforming Cultures. New York: Oxford University Press.

Leavitt, P. A., Covarrubias, R., Perez, Y. A., \& Fryberg, S. A. (2015). "Frozen in time": The impact of Native American media representations on identity and self-understanding. Journal of Social Issues, 71, 39-53.

Lorde, A. (1979). The master's tools will never dismantle the master's house. In Sister Outsider: Essays and Speeches (Freedom: CA: Crossing, 1984): 110-113.

Lysne, M., \& Levy, G. D. (1997). Differences in ethnic identity in Native American adolescents as a function of school context. Journal of Adolescent Research, 12, 372-388.

Manago, A., Santer, N., Barsigian, L. L., \& Walsh, A. (2020). Social media as tools for cultural change in the transition to adulthood. In K. McLean (Eds.) Cultural Methodologies in 
Psychology: Describing and Transforming Cultures. New York: Oxford University Press.

Manuelito, B. K. (2015). Creating space for an Indigenous approach to digital storytelling:" Living breath" of survivance within an Anishinaabe community in northern Michigan (PhD Dissertation). Antioch University, Culver City, CA.

Markstrom, C. A. (2011). Identity formation of American Indian adolescents: Local, national, and global considerations. Journal of Research on Adolescence, 21, 519-535.

McAdams, D. P., \& McLean, K. C. (2013). Narrative identity. Current Directions in Psychological Science, 22, 233-238.

McLean, K. C., Lilgendahl, J. P., Fordham, C., Alpert, E., Marsden, E., Szymanowski, K., \& McAdams, D. P. (2018). Identity development in cultural context: The role of deviating from master narratives. Journal of Personality, 86, 631-651.

McLean, K. C., \& Syed, M. (2015). Personal, master, and alternative narratives: An integrative framework for understanding identity development in context. Human Development, 58, 318-349.

Mieder, W. (1993). "The only good Indian is a dead Indian": History and meaning of a proverbial stereotype. Journal of American Folklore, 106, 38-60.

Moorehead Jr., V. (2014). Digital storytelling and urban American Indians: Exploring participant experiences (PsyD Dissertation). The Wright Institute, Berkeley.

Moorehead, V., \& Lafromboise, T. D. (2014). Healing one story at a time: American Indian/Alaska Native social justices. In J. Diaz, Z. Franco, \& B. K. Nastasi (Eds.). The Praeger Handbook of Social Justice and Psychology (Vol. 1, pp. 135-154).

Originative. In The Merriam-Webster.com Dictionary. Retrieved on January 14, 2020, from https://www.merriam-webster.com/dictionary/originative 
Palacios, J. (2012). Traditional storytelling in the digital era. Fourth World Journal, 11, 41-56.

Palacios, J. F., Salem, B., Hodge, F. S., Albarrán, C. R., Anaebere, A., \& Hayes-Bautista, T. M. (2015). Storytelling: A qualitative tool to promote health among vulnerable populations. Journal of Transcultural Nursing, 26, 346-353.

Palmer, M. H. (2016). Kiowa Storytelling Around a Map. In Charles Travis \& A. von Lünen (Eds.), The Digital Arts and Humanities (pp. 63-73). https://doi.org/10.1007/978-3-319-40953-5_4

Ponterotto, J. G. (2005). Qualitative research in counseling psychology: A primer on research paradigms and philosophy of science. Journal of Counseling Psychology, 52, 126-136.

Powell, T. B., Weems, W., \& Owle, F. (2007). Native/American digital storytelling: Situating the Cherokee oral tradition within American literary history. Literature Compass, 4, 123.

Rogers, L. O, Moffitt, U., \& Jones, C. M. (2020). Listening for culture: Using interviews to capture stories of identity in context. In K. McLean (Eds.) Cultural Methodologies in Psychology: Describing and Transforming Cultures. New York: Oxford University Press.

Simpson, A. (2014). Mohawk interruptus: Political life across the borders of settler states. Durham, NC: Duke University Press.

Singer, J. A. (2004). Narrative identity and meaning making across the adult lifespan: An introduction. Journal of Personality, 72, 437-460.

Smith, L. T. (2012). Decolonizing methodologies: Research and indigenous peoples (2nd Ed.). London, UK: Zed Books. (Original work published 1999). 
Smithies, J., \& Webster, G. (1998). Community involvement in health: from passive recipients to active participants. London, UK: Routledge.

Society of Indian Psychologists \& García, M. A. (ed.). (2014) Commentary on the American Psychological Association's (APA) Ethical Principles of Psychologists and Code of Conduct. Retrieved from https://www.aiansip.org/commentary.html

Syed, M., \& Mitchell, L. L. (2015). Temporal identity integration as a core developmental process. In Scott, R. \& Kosslyn, S. (Eds.) Emerging Trends in the Social and Behavioral Sciences: An Interdisciplinary, Searchable, and Linkable Resource (pp. 1-15).

Trimble, J. E. (1987). Self-perception and perceived alienation among American Indians. Journal of Community Psychology, 15, 316-333.

Vera, E. M., \& Speight, S. L. (2003). Multicultural competence, social justice, and counseling psychology: Expanding our roles. The Counseling Psychologist, 31, 253-272.

Vivienne, S. (2011). Trans Digital Storytelling: Everyday activism, mutable identity and the problem of visibility. Gay and Lesbian Issues and Psychology Review, 7, 43-54.

Vivienne, S., \& Burgess, J. (2013). The remediation of the personal photograph and the politics of self-representation in digital storytelling. Journal of Material Culture, 18, 279-298.

Walters, K. L., Mohammed, S. A., Evans-Campbell, T., Beltrán, R. E., Chae, D. H., \& Duran, B. (2011). Bodies don't just tell stories, they tell histories: Embodiment of historical trauma among American Indians and Alaska Natives. Du Bois Review: Social Science Research on Race, 8, 179-189.

Walters, K. L., Johnson-Jennings, M., Stroud, S., Rasmus, S., Charles, B., John, S., ... \& Lowe, J. (2020). Growing from our roots: Strategies for developing culturally grounded health 
promotion interventions in American Indian, Alaska Native, and Native Hawaiian communities. Prevention Science, 21, 54-64.

Weststrate, N. M. (2020). Using life story methods to capture cultural-historical dimensions of LGBTQ+ identity development across the generations. In K. McLean (Eds.) Cultural Methodologies in Psychology: Describing and Transforming Cultures. New York: Oxford University Press.

Wexler, L., Gubrium, A., Griffin, M., \& DiFulvio, G. (2013). Promoting positive youth development and highlighting reasons for living in northwest Alaska through digital storytelling. Health Promotion Practice, 14, 617-623.

Whitbeck, L. B., Adams, G. W., Hoyt, D. R., \& Chen, X. (2004). Conceptualizing and measuring historical trauma among American Indian people. American Journal of Community Psychology, 33, 119-130.

Wilson, S. (2001). What is an Indigenous research methodology? Canadian Journal of Native Education, 25, 175-179.

Wilson, S., Breen, A. V., DuPré, L. (2020). Mining for culture or researching for justice? Unsettling psychology through indigenist conversation. In K. McLean (Eds.) Cultural Methodologies in Psychology: Describing and Transforming Cultures. New York: Oxford University Press.

Wolfe, P. (2006). Settler Colonialism and the Elimination of the Native. Journal of Genocide Research, 8, 387-409.

Worthen, M., Veale, A., McKay, S., \& Wessells, M. (2019). The transformative and emancipatory potential of participatory evaluation: reflections from a participatory action research study with war-affected young mothers. Oxford Development Studies, 47, 154170. 
Table 1

Participants' Self-Identified Tribal Communities or Affiliations in Alphabetical Order

\begin{tabular}{|c|c|}
\hline \multicolumn{2}{|l|}{ Tribal Communities or Affiliations } \\
\hline Alaska Native & \\
\hline Tlingit and Haida & 1 \\
\hline \multicolumn{2}{|l|}{ First Nations } \\
\hline Beardy's and Okemasis Cree Nation & 1 \\
\hline \multicolumn{2}{|l|}{ Native American } \\
\hline Bois Forte Band of Ojibwe & 7 \\
\hline Cheyenne River Sioux Tribe & 1 \\
\hline Chickasaw Nation & 2 \\
\hline Diné & 2 \\
\hline Fond du Lac Band of Lake Superior Chippewa & 6 \\
\hline Grand Portage Band of Lake Superior Chippewa & 3 \\
\hline Hocąk & 1 \\
\hline Lac Courte Oreilles Ojibwe & 1 \\
\hline Lakota & 1 \\
\hline Leech Lake Band of Ojibwe & 2 \\
\hline Lower Brule Sioux & 2 \\
\hline Oglala Lakota & 2 \\
\hline Ojibwe & 1 \\
\hline Oneida Nation of Wisconsin & 1 \\
\hline Quechan Tribe & 1 \\
\hline Red Cliff Band of Lake Superior Chippewa & 2 \\
\hline Red Lake Ojibwe & 10 \\
\hline Rosebud Sioux & 1 \\
\hline Seneca Nation & 3 \\
\hline Sisseton-Wahpeton Sioux Tribe & 1 \\
\hline Turtle Mountain Band of Ojibwe & 2 \\
\hline White Earth Ojibwe & 10 \\
\hline \multicolumn{2}{|l|}{ Multiple tribal communities or affiliations } \\
\hline Dakota and Ojibwe & 1 \\
\hline Gros Ventre, Cheyenne, and Ojibwe & 1 \\
\hline Lakota Oohenunpa and Oglala Lakota & 1 \\
\hline Menominee and Navajo & 1 \\
\hline Menominee and Potawatomi & 1 \\
\hline Metis and Sault Ste. Marie Ojibwe & 1 \\
\hline Oglala Lakota Sioux and Kule Wicasa Sioux & 1 \\
\hline $\begin{array}{l}\text { Oneida Nation of Wisconsin and Stockbridge-Munsee Band of the } \\
\text { Mohicans }\end{array}$ & 1 \\
\hline White Earth Ojibwe and Winnebago & 1 \\
\hline Unknown tribal communities or affiliations & 2 \\
\hline
\end{tabular}

Note. Categories reflect the language participants used to describe their tribal communities or affiliations. 
Table 2

Participant Demographics and Descriptive Statistics

\begin{tabular}{|c|c|c|c|}
\hline Demographics & $n$ & $\%$ & Misc. \\
\hline \multicolumn{4}{|l|}{ Gender } \\
\hline Female & 53 & $70.7 \%$ & -- \\
\hline Male & 17 & $22.7 \%$ & -- \\
\hline Two Spirit & 4 & $5.3 \%$ & -- \\
\hline Other & 1 & $1.3 \%$ & -- \\
\hline \multicolumn{4}{|l|}{ Level of Education } \\
\hline Some High School & 1 & $1 . \overline{3} \%$ & -- \\
\hline High School Degree or Equivalent & 18 & $24 \%$ & -- \\
\hline Associate's Degree or Equivalent & 21 & $28 \%$ & -- \\
\hline Bachelor's Degree & 21 & $28 \%$ & -- \\
\hline Master's Degree & 10 & $13 . \overline{3} \%$ & -- \\
\hline Doctoral or Professional Degree & 4 & $5 . \overline{3} \%$ & -- \\
\hline \multicolumn{4}{|l|}{ Source of Income } \\
\hline Full Time Employment & 39 & $52 \%$ & -- \\
\hline Part Time Employment & 14 & $18.7 \%$ & -- \\
\hline Pension & 1 & $1.3 \%$ & -- \\
\hline Public Assistance & 3 & $4 \%$ & -- \\
\hline Supplemental Security Income (SSI) & 4 & $5.3 \%$ & -- \\
\hline Unemployment Benefits & 2 & $2.7 \%$ & -- \\
\hline+1 Source of Income & 11 & $14.7 \%$ & -- \\
\hline No Response & 1 & $1.3 \%$ & -- \\
\hline \multicolumn{4}{|l|}{ Age in Years } \\
\hline $18-29$ & 15 & $20 \%$ & -- \\
\hline $30-39$ & 21 & $28 \%$ & -- \\
\hline $40-49$ & 10 & $13.3 \%$ & -- \\
\hline $50-59$ & 9 & $12 \%$ & -- \\
\hline $60-69$ & 12 & $16 \%$ & -- \\
\hline $70+$ & 8 & $10.7 \%$ & -- \\
\hline$M$ & -- & -- & 45.31 \\
\hline$S D$ & -- & -- & 16.90 \\
\hline Range & -- & -- & $19-80$ \\
\hline
\end{tabular}


Figure 1

OrigiNatives Website Legend
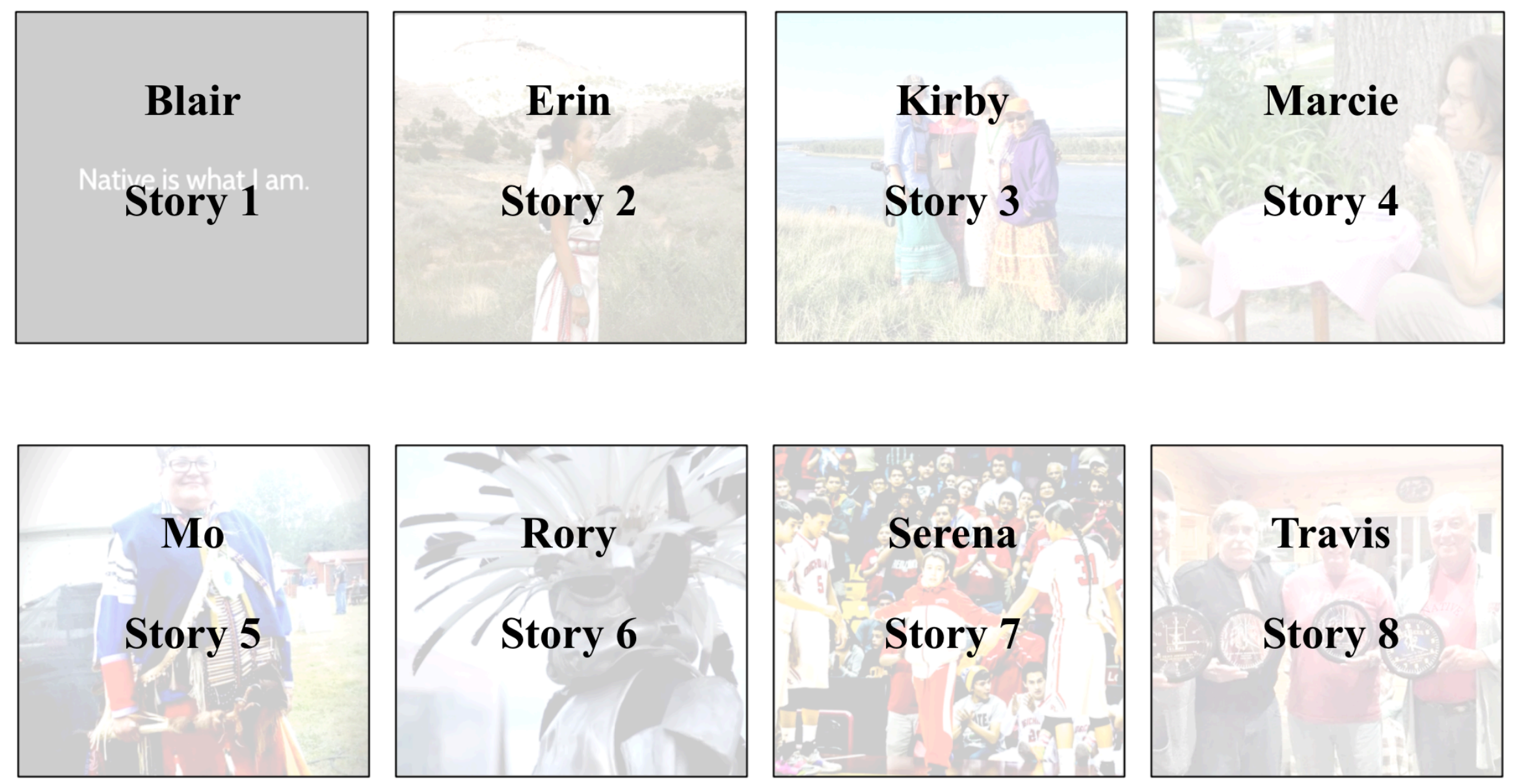

Note. Digital stories corresponding to website (https://umn-latis.github.io/digital-stories/) and Digital Story Narratives on the OSF page (https://osf.io/4zsh6/). 